\title{
CUSTO DE PRODUÇÃO DE AMORA-PRETA EM REGIÃO TROPICAL ${ }^{1}$
}

\author{
LÍSIA BORGES ATTILIO², APARECIDA CONCEIÇÃO BOLIANI³, \\ MARIA APARECIDA ANSELMO TARSITANO
}

RESUMO-O cultivo da amora-preta é recente no Brasil. A espécie apresenta elevada adaptabilidade, baixa exigência em frio, facilidade de manejo, rusticidade e pouca utilização de defensivos agrícolas. É uma fruta que vem despertando elevada atenção dos consumidores devido à presença de compostos fenólicos com propriedades antioxidantes. Com este trabalho, objetivou-se analisar o custo de produção do cultivo da amora-preta, em primeiro ano de produção. Para estimar a matriz de coeficientes técnicos e os custos de produção, em 2007, os preços de venda foram levantados junto a um produtor, e o restante das informações foi obtido de um experimento. De acordo com os dados e os cálculos de custos, a primeira produção da cultura foi de 3.000 kg.ha-1 , com custo de implantação e condução, no primeiro ano, de R\$ 8.710,63, e no segundo ano, apresentou custo de R \$ 6.467,50. O custo de produção foi relativamente baixo comparado com outras frutíferas perenes cultivadas na região, evidenciando que esta atividade pode ser mais uma alternativa de renda para agricultura familiar.

Termos para Indexação: Rubus sp, pequenas frutas.

\section{PRODUTION COST OF BLACKBERRY CROP IN A TROPICAL AREA}

\begin{abstract}
Growing blackberry is quite recent in Brazil. The species gets easily adapted, with low cooling demand and low use of agrochemicals. This fruit has drawn the attention of the consumers due to the presence of phenolic compounds with anti-oxidizing features. This research aimed at analyzing blackberry crops economically, on the first production year. In order to estimate the technical coefficients matrix and the producing costs, the prices were surveyed from a producer and the rest of the data were obtained from an experiment in 2007. According to the data and the calculated costs, in the first yield was $3000 \mathrm{~kg} \mathrm{ha}^{-1}$, with cost producing and cultivation for the first year of $\mathrm{R} \$ 8,710.63$ and the second year had a cost of R\$ 6,467.50. The producing costs were low in comparison with others perennials fruit crops in this region, showing that this activity can be an alternative for smallholders.
\end{abstract}

Index terms: Rubus sp, small fruits

\section{INTRODUÇÃO}

A amoreira-preta faz parte de um grande grupo de plantas do gênero Rubus, pertencente à família Rosaceae, na qual existem outros gêneros de importância (Malus, Prunus, Pyrus entre outros) para a fruticultura brasileira (ANTUNES, 2002).

Os frutos da amoreira-preta que podem ser utilizados para confecção de geleias, doces, sorvetes e polpas, contêm 85\% de água e 10\% de carboidratos, além de compostos funcionais, como ácido elágico e antocianinas (ANTUNES et al., 2002).

Apesar da existência de espécies silvestres no Brasil, o cultivo da amora-preta só tomou impulso a partir da introdução de cultivares provenientes do
Estado de Arkansas (EUA) pela Embrapa, em 1974, sendo difundida nos estados do Sul e Sudeste. Em 2003, a produção brasileira foi de 1.300 toneladas em uma área de 110 hectares, dentre as pequenas frutas, perdendo apenas para o morango (PAGOT \& HOFFMANN, 2003).

A espécie apresenta elevada adaptabilidade e baixa exigência em frio. Os resultados obtidos na região serrana de Minas Gerais, próxima a Poços de Caldas, têm sido promissores, possibilitando produção antecipada em relação à maioria das tradicionais regiões produtoras localizadas ao Sul do País, favorecendo o alcance do mercado e a rentabilidade do cultivo (PAGOT \& HOFFMANN, 2003).

Trata-se de uma planta rústica, apresenta

'( Trabalho 276-08). Recebido em: 11-11-2008. Aceito para publicação em: 21-07-2009. Parte da dissertação do primeiro autor, apresentada à FE/UNESP para obtenção do título de Mestre.

${ }^{2}$ Doutoranda em Ciências, PPG Fitotecnia Vegetal, USP/ESALQ, C. P. 09, CEP 13418-900 - Piracicaba-SP. e-mail: lisiaborges@gmail.com.

${ }^{3}$ Profa Adjunto do Departamento de Fitotecnia, Tecnologia de Alimentos e Sócio-Economia da FE/UNESP, Av. Brasil, 56, C. P. 31. Ilha Solteira - São Paulo - CEP 15385-000, E-mail: boliani@agr.feis.unesp.br/maat@agr.feis.unesp.br. 
frutas de alta qualidade nutricional, e o seu cultivo vem crescendo nos Estados do Rio Grande do Sul e São Paulo. Em Minas Gerais, é considerada uma das opções para a pequena propriedade agrícola (ANTUNES, 2002).

No Estado de São Paulo, a região de Campos do Jordão é a mais representativa, e em Minas Gerais os primeiros plantios estão sendo realizados em Caldas, Baependi e Barbacena. Regiões de clima temperado de altitude são as preferencialmente exploradas (PIO et al., 2008).

No Rio Grande do Sul, a amoreira-preta tem tido grande aceitação pelos produtores, devido ao baixo custo de produção, facilidade de manejo, rusticidade e pouca utilização de defensivos agrícolas. A produtividade pode alcançar até $10.000 \mathrm{~kg} \cdot \mathrm{ha}^{-1}$. ano $^{-1}$ sob condições adequadas (ANTUNES, 2002). Segundo Santos et al. (1997), a produção de amora-preta para regiões de clima temperado é de 5.000 kg.ha ${ }^{-1}$, 7.500 kg.ha- ${ }^{-1}, 12.000$ kg.ha-1 para o primeiro, segundo e terceiros anos de produção, respectivamente.

A amoreira-preta é uma cultura perene, e sua vida econômica varia de doze a quinze anos (SANTOS et al., 1997).

Informações sobre produção e comercialização de amora-preta, no Brasil, são escassas (ANTUNES, 2002). Entretanto, segundo dados apresentados pela CEASA-RS, de preços e volume, na safra gaúcha de 2006 iniciada em outubro, a fruta alcançou preços por quilo de $\mathrm{R} \$ 6,50, \mathrm{R} \$ 2,82$ e $\mathrm{R} \$ 2,66$, em outubro, novembro e dezembro, respectivamente (CEASA, 2007). No CEAGESP, em 2008, a fruta foi comercializada de R\$12,00 a R \$ 18,00 por quilo, em volumes pequenos (FRUTAS LUMA, 2009).

Apesar de ser caracterizada como uma fruteira rústica, com baixos custos de implantação e condução, são escassas as informações sobre os custos de implantação e condução da cultura.

Com este trabalho, objetivou-se avaliar o custo de produção da cultura da amoreira-preta na região de Selvíria-MS. Sendo avaliado o custo de implantação e a condução do primeiro ano de produção, e analisada a viabilidade como uma alternativa na região.

\section{MATERIAL E MÉTODOS}

O levantamento de dados foi realizado na região de Selvíria-MS, durante 2007, em um experimento de primeiro ano de produção (2 anos), conduzido na Fazenda de Ensino Pesquisa e Extensão (FEPE) da Universidade Estadual Paulista (UNESP) - Câmpus de Ilha Solteira, localizada no município de Selvíria-MS, no encontro aproximado das coor-

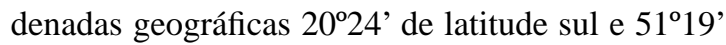
de longitude oeste de Greenwich, com altitude em torno de $335 \mathrm{~m}$. Os preços recebidos foram fornecidos por um produtor iniciante no cultivo da fruta, no município de Selvíria-MS, obtidos na venda da fruta na feira local, descontados o gasto de $20 \%$ do valor pago referente à comercialização.

O clima da região é classificado como clima tropical úmido, com estação chuvosa no verão e seca no inverno (Aw de Köeppen), apresentando temperatura média anual de $23,7^{\circ} \mathrm{C}$ e precipitação total anual de $1.300 \mathrm{~mm}$. O solo, reclassificado segundo o Sistema Brasileiro de Classificação de Solos (EMBRAPA, 1999), é um Latossolo Vermelho distroférrico típico muito argiloso, cuja vegetação original era cerrado.

O experimento foi implantado em 07 de junho de 2006 e possui 80 plantas de amoreira-preta, propagadas por estacas cv. Tupy, cultivadas num espaçamento de 3,0 x 1,0m, conduzidas em espaldeira em $\mathrm{T}$, com 0,5m de altura, e densidade de plantio de 3.333 plantas/ha.

A primeira colheita ocorreu do final de setembro até o início de novembro de 2007. Os tratos culturais realizados na cultura durante a condução do experimento foram os convencionais recomendados para a cultura, nas regiões tradicionais produtoras.

Para cálculo da implantação da cultura, considerou-se para aração, gradagem, calagem, grade niveladora, abertura de cova e montagem dos mourões, o custo hora/máquina de um trator de 75 cv 4x2. Para as demais operações mecanizadas, utilizou-se para o cálculo o custo da hora/máquina de um microtrator com $14 \mathrm{cv} 4 \mathrm{x} 2$.

Durante o período de condução deste trabalho, foram realizados levantamento dos tratos culturais e preço médio dos insumos e defensivos utilizados para obter o custo operacional de produção, seguindo a estrutura utilizada pelo Instituto de Economia Agrícola - IEA, conforme Matsunaga et al. (1976).

Nas operações referentes ao sistema de cultivo, foram computados materiais consumidos e o tempo necessário de máquinas e mão de obra para a realização de cada operação, definindo os coeficientes técnicos em termos de hora/máquina, homem/dia e as quantidades utilizadas dos materiais por unidade de área.

Para as despesas manuais, considerou-se o valor da diária na região de $\mathrm{R} \$ 25,00$, a taxa de 8,75 \%a.a. sobre a metade do custo operacional efetivo como juros de custeio e $5 \%$ sobre o COE para outras despesas operacionais.

As depreciações foram calculadas, utilizando- 
se do método linear. Consideraram-se 10 anos como vida útil total da amoreira.

Os dados de produção foram utilizados para estimar os custos com a colheita, embalagem e para estimar o custo por kg e o índice de lucratividade.

As colheitas foram realizadas de 26 de setembro a 8 de novembro de 2007, em intervalos de dois dias, sendo colhidas as frutas que se apresentavam com coloração preta.

\section{RESULTADOS E DISCUSSÃO}

O valor do investimento inicial em materiais para implantação e construção da espaldeira em 1 ha, foi de R\$ 5.945,40 (Tabela 1). As despesas com os mourões de eucalipto tratado representam $81,6 \%$ do total. O tempo estimado para depreciação da espaldeira foi de 10 anos, totalizando R\$ 594,54 de depreciação anual.

O custo operacional total do $1^{\circ}$ ano, implan-

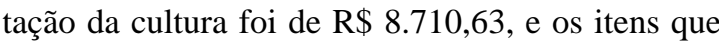
mais contribuíram com o valor do COT foram as mudas, com $38,26 \%$, seguidas dos fertilizantes, que representaram 22,23\%, (Tabela 2).

No segundo ano da cultura, iniciaramse as colheitas dos frutos, com rendimento de $3.000 \mathrm{~kg} \cdot \mathrm{ha}^{-1}$, segundo dados do experimento realizado na FEPE, em 2007.

Com o início de produção, foram computados os custos com as colheitas e embalagens. As colheitas para o mercado in natura foram realizadas de dois em dois dias, totalizando aproximadamente 20 colheitas no período de produção, sendo necessários 2 homens.dia-1 para cada colheita.
O COT para o $2^{\circ}$ ano foi de $\mathrm{R} \$ 6.467,50$, tendo sido o item de maior custo o adubo formulado, representando $28,06 \%$, seguido da mão de obra com a colheita, que contribuiu com $15,46 \%$ do COT. O custo por quilo de amora-preta produzida no $2^{\circ}$ ano foi de R\$ 2,16 (Tabela 3).

Levando em conta a produtividade média de 3.000 kg.ha ${ }^{-1}$ obtida no segundo ano da cultura e o preço de venda recebido pelo produtor, descontados o gasto de $20 \%$ do valor pago referente à comercialização, de $\mathrm{R} \$ 8,00$ por quilo, a receita bruta foi de R\$ 24.000,00, o lucro operacional de R\$17.532,50 e o preço de equilíbrio, preço mínimo para cobrir os custos de produção, foi de R\$2,16. Deve-se ressaltar que esses valores não representam valores médios para a região, são dados de um produtor, que trabalha com outras frutíferas e está iniciando o cultivo da amora.

Considerando-se os custos de implantação não tão elevados, quando comparados com outras frutíferas, como a uva Niágara, que, na mesma região, custa $\mathrm{R} \$ 20.000,00$ por hectare (AGRIANUAL, 2009), assim como os custos com a condução da cultura e a facilidade de condução, esta pode ser recomendada como cultura alternativa para pequenos produtores da região, porém mais estudos devem ser feitos, observando-se a produção média obtida nos anos subsequentes na região e o consumo da fruta no mercado regional.

TABELA 1- Descrição dos materiais, quantidade e valor em reais para a montagem de 1 ha de espaldeira para condução de amoreira-preta, espaçamento de 3,0x1,0 m, com densidade de plantio de 3.333 plantas.ha ${ }^{-1}$. Selvíria-MS, 2007.

\begin{tabular}{lcccc}
\hline Decrição - Materiais & Unidade & $\begin{array}{c}\text { Valor unitário } \\
(\mathbf{R S})\end{array}$ & Quant. & $\begin{array}{c}\text { Valor Total } \\
(\mathbf{R S )}\end{array}$ \\
\hline Mourões de eucalipto tratados (1,5mx0,1m) & un & 7,00 & 693 & $4.851,00$ \\
Ripas de madeira & $\mathrm{m}$ & 0,80 & 693 & 554,40 \\
Arame 8 & $\mathrm{kg}$ & 6,00 & 90 & 540,00 \\
Total & & & & $\mathbf{5 . 9 4 5 , 4 0}$ \\
\hline
\end{tabular}


TABELA 2 - Descrição das operações e materiais, especificação das unidades, valor unitário, quantidade e valor total para implantação e condução de $1^{\circ}$ ano de amoreira-preta. Valores estimados para

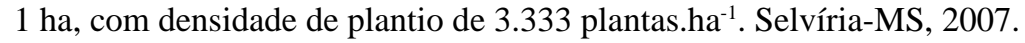

\begin{tabular}{|c|c|c|c|c|c|}
\hline DESCRIÇÃO & Especificação & Valor un. & Qtde & Total (R\$) & $\%$ \\
\hline \multirow{2}{*}{\multicolumn{6}{|c|}{$\begin{array}{l}\text { A- OPERAÇÕES MECANIZADAS } \\
\text { a1. Preparo do solo }\end{array}$}} \\
\hline & & & & & \\
\hline Gradagem & $\mathrm{HM}$ & 42,00 & 0,86 & 36,12 & 0,41 \\
\hline Aração & $\mathrm{HM}$ & 42,00 & 2 & 84,00 & 0,96 \\
\hline Calagem & $\mathrm{HM}$ & 42,00 & 1,3 & 54,60 & 0,63 \\
\hline Grade niveladora & $\mathrm{HM}$ & 42,00 & 0,84 & 35,28 & 0,41 \\
\hline \multicolumn{6}{|l|}{ a2. Implantação } \\
\hline Perfuração para palanques & $\mathrm{HM}$ & 42,00 & 6 & 252,00 & 2,89 \\
\hline Montagem dos palanques & HM & 42,00 & 3 & 126,00 & 1,45 \\
\hline \multicolumn{6}{|l|}{ a3. Tratos Culturais } \\
\hline Roçada mecânica (2x) & HM & 19,00 & 6 & 114,00 & 1,31 \\
\hline Subtotal A & & & & 702,00 & 8,06 \\
\hline \multicolumn{6}{|l|}{ B- OPERAÇÕES MANUAIS } \\
\hline \multicolumn{6}{|l|}{ b1. Preparo do solo } \\
\hline Calagem & HD & 25,00 & 5 & 125,00 & 1,44 \\
\hline Adubação das covas & HD & 25,00 & 4 & 100,00 & 1,15 \\
\hline \multicolumn{6}{|l|}{ b2. Implantação } \\
\hline Perfuração das covas de plantio & HD & 25,00 & 2 & 50,00 & 0,57 \\
\hline Montagem dos palanques & HD & 25,00 & 3 & 75,00 & 0,86 \\
\hline Plantio & HD & 25,00 & 3 & 75,00 & 0,86 \\
\hline Tutoramento & HD & 25,00 & 2 & 50,00 & 0,57 \\
\hline \multicolumn{6}{|l|}{ b3. tratos culturais } \\
\hline Adubação & HD & 25,00 & 2 & 50,00 & 0,57 \\
\hline Capina química (3x) & HD & 25,00 & 3 & 75,00 & 0,86 \\
\hline Capina manual (3x) & HD & 25,00 & 9 & 225,00 & 2,58 \\
\hline Aplicação de formicida & HD & 25,00 & 1 & 25,00 & 0,29 \\
\hline Subtotal B & & & & 850,00 & 9,76 \\
\hline \multicolumn{6}{|l|}{ C. MATERIAL } \\
\hline \multicolumn{6}{|l|}{ c1.Fertilizantes } \\
\hline Calcário & $\mathrm{t}$ & 95,00 & 2 & 190,00 & 2,18 \\
\hline Esterco de curral & $\mathrm{t}$ & 25,00 & 1,6 & 40,00 & 0,46 \\
\hline Super simples & $\mathrm{t}$ & 450,00 & 1 & 450,00 & 5,17 \\
\hline Cloreto de Potássio & $\mathrm{kg}$ & 1,13 & 264 & 297,79 & 3,42 \\
\hline Fórmula 8-28-16 & $\mathrm{t}$ & $1.173,34$ & 1,65 & $1.936,01$ & 22,23 \\
\hline \multicolumn{6}{|l|}{ c2. Mudas } \\
\hline Mudas & un & 1,00 & 3.333 & $3.333,00$ & 38,26 \\
\hline \multicolumn{6}{|l|}{ c3. Fitossanitários } \\
\hline Glifosato (3x) & $\mathrm{L}$ & 25,00 & 6 & 150,00 & 1,72 \\
\hline Formicida & $\mathrm{kg}$ & 7,60 & 2 & 15,20 & 0,17 \\
\hline Subtotal C & & & & $6.412,00$ & 73,61 \\
\hline Custo operacional efetivo (C.O.E.) & & & & $7.964,00$ & 91,43 \\
\hline Outras despesas & & & & 398,20 & 4,57 \\
\hline Juros de custeio & & & & 348,43 & 4,00 \\
\hline Custo operacional total (C.O.T.) & & & & $8.710,63$ & \\
\hline
\end{tabular}


TABELA 3 - Descrição das operações e materiais, especificação das unidades, valor unitário, quantidade e valor total para $2^{\circ}$ ano de amora-preta. Valores estimados para 1 ha, com densidade de plantio

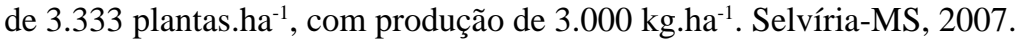

\begin{tabular}{|c|c|c|c|c|c|}
\hline DESCRIÇÃO & Especificação & Valor un. & Qtde & Total (R\$) & $\%$ \\
\hline \multicolumn{6}{|l|}{ A- OPERAÇÕES MECANIZADAS } \\
\hline \multicolumn{6}{|l|}{ a3. Tratos Culturais } \\
\hline Roçada mecânica (2x) & HM & 19,00 & 6 & 114,00 & 1,76 \\
\hline \multicolumn{6}{|l|}{ a4. Colheita } \\
\hline Colheita & HM & 19,00 & 15 & 285,00 & 4,41 \\
\hline Subtotal A & & & & 399,00 & 6,17 \\
\hline \multicolumn{6}{|l|}{ B- OPERAÇÕES MANUAIS } \\
\hline \multicolumn{6}{|l|}{ b3. tratos culturais } \\
\hline Poda & HD & 25,00 & 4 & 100,00 & 1,55 \\
\hline Adubação & HD & 25,00 & 2 & 50,00 & 0,77 \\
\hline Capina química (3x) & HD & 25,00 & 3 & 75,00 & 1,16 \\
\hline Capina manual (3x) & HD & 25,00 & 9 & 225,00 & 3,48 \\
\hline Pulverização de cianamida hidrogenada & HD & 25,00 & 3 & 75,00 & 1,16 \\
\hline Aplicação de formicida & HD & 25,00 & 1 & 25,00 & 0,39 \\
\hline \multicolumn{6}{|l|}{ b4. Colheita } \\
\hline Colheita (20x) & $\mathrm{HD}$ & 25,00 & 40 & $1.000,00$ & 15,46 \\
\hline Subtotal B & & & & $1.550,00$ & 23,97 \\
\hline \multicolumn{6}{|l|}{ C. MATERIAL } \\
\hline \multicolumn{6}{|l|}{ c1.Fertilizantes } \\
\hline Esterco de curral & $\mathrm{t}$ & 25,00 & 1,6 & 40,00 & 0,62 \\
\hline Fórmula 20-5-20 & $\mathrm{t}$ & $1.100,00$ & 1,65 & $1.815,00$ & 28,06 \\
\hline \multicolumn{6}{|l|}{ c3. Fitossanitários } \\
\hline Glifosato (3x) & $\mathrm{L}$ & 25,00 & 6 & 150,00 & 2,32 \\
\hline Formicida & $\mathrm{kg}$ & 7,60 & 2 & 15,20 & 0,24 \\
\hline Cianamida hidrogenada & $\mathrm{L}$ & 38,00 & 8 & 304,00 & 4,70 \\
\hline \multicolumn{6}{|l|}{ c4. Colheita } \\
\hline Embalagens & un & 0,20 & 1.500 & 300,00 & 4,64 \\
\hline Subtotal C & & & & $2.624,20$ & 40,58 \\
\hline Custo operacional efetivo (C.O.E.) & & & & $4.573,20$ & 70,71 \\
\hline Outras despesas & & & & 228,66 & 3,54 \\
\hline Juros de custeio & & & & 200,08 & 3,09 \\
\hline Depreciação do pomar & & & & 871,06 & 13,47 \\
\hline Depreciação da espaldeira & & & & 594,50 & 9,19 \\
\hline Custo operacional total (C.O.T.) & & & & $6.467,50$ & \\
\hline Custo por $\mathrm{Kg}$ & & & & 2,16 & \\
\hline
\end{tabular}




\section{CONCLUSÕES}

1-O valor necessário para construção de 1 ha de espaldeira para condução de amoreira-preta e mais os custos com a implantação da cultura no $1^{\circ}$ ano atingiu $\mathrm{R} \$ 8.710,63$, o custo de produção para o $2^{\circ}$ ano, quando se iniciou a produção, foi de $\mathrm{R} \$ 6.467,50$. A cultura no primeiro ano de produção teve rendimento de $3.000 \mathrm{~kg} \cdot \mathrm{ha}^{-1}$. O preço mínimo por quilo de produto deve ser $\mathrm{R} \$ 2,16$.

2-Como a cultura é nova na região, deve ser acompanhada nos próximos anos para verificar se os dados permanecem, considerando as despesas com os tratos culturais e a colheita da fruta, as produtividades das próximas safras e os preços médios pagos ao produtor.

\section{REFERÊNCIAS}

AGRIANUAL: anuário da agricultura brasileira. São Paulo: FNP, 2009. p. 256-257.

ANTUNES, L. E. C. Amora-preta: nova opção de cultivo no brasil. Ciência Rural. Santa Maria, v.32, n.1, p.151-158, 2002.

ANTUNES, L. E. C.; REGINA, M. A.; DUARTE FILHO, J. A cultura da amora-preta. Belo Horizonte: EPAMIG, 2002. 28 p. (Boletim Técnico, 69)

CEASA-RS CENTRAIS DE ABASTECIMENTO DO ESTADO DO RIO GRANDE DO SUL. Preço amora-preta. [mensagem pessoal] Mensagem recebida por: <lbattilio@aluno.feis.unesp.br>. em: 14 mar. 2007.
EMBRAPA Sistema brasileiro de classificação de solos. Rio de Janeiro: Empresa Brasileira de Pesquisa Agropecuária - CNPSO, 1999. 421p.

FRUTAS LUMA. Preço amora-preta. [mensagem pessoal] Mensagem recebida por: <lisiaborges@ aluno.feis.unesp.br>. em: 05 mar. 2009.

MATSUNAGA, M.; BEMELMANS, P. F.; TOLEDO, P. E. N. de; DULLEY, R. D.; OKAWA, H.; PEDROSO, I. A. Metodologia de custo de produção utilizado pelo IEA. Agricultura em São Paulo, São Paulo, v. 23, n. 1, p. 123-139, 1976.

PAGOT, E.; HOFFMANN, A. Produção de pequenas frutas no Brasil. . In: SEMINÁRIO BRASILEIRO SOBRE PEQUENAS FRUTAS, 1., 2003, Bento Gonçalves. Anais... Bento Gonçalves: Embrapa Uva e Vinho, 2003. p. 31 - 32. (Documentos, 37)

PIO, R.; CHAGAS, E. A.; BARBOSA, W.; BUENO, S. C. S.; Amora-Preta: nova opção para a diversificação das propriedades frutícolas. Disponível em: <www.portaldoagronegocio.com.br>. Acesso em: 6 jan. 2008.

SANTOS, A.M.; RASEIRA, M.C.B.; MADAIL, J.C.M. Amora-preta. 2. ed. Brasília: Embrapa-SPI, 1997. 61 p. (Coleção Plantar, 33). 